\title{
Researchers bring fishermen on board
}

How is climate change likely to affect the abundance of marine animals? And can tensions between scientists and fishermen be reduced if the latter can become involved in research by collecting data during their work? Both questions are to be addressed by a new US research programme which aims to generate knowledge that will be essential for the establishment and maintenance of sustainable fisheries.

The GLOBEC (Global Oceans Ecosystem Dynamics) programme is funded by the US National Science Foundation, the National Oceanic and Atmospheric Administration and the National Marine Fisheries Service. It focuses on three sites: the Northeast Pacific, the Antarctic region, and the Georges Bank fishery in the Northwest Atlantic.

The most prominent is the Georges Bank study, as it will draw on data gathered both by research scientists and commercial fishermen. The idea is that such collaboration could forge ties between communities that have often been at odds, while eventually paving the way for more effective fisheries management strategies.

\section{Search for fluctuations}

Scientists are trying to see how populations of zooplankton, copepods (small marine crustaceans) and imperilled cod and haddock fluctuate in Georges Bank in response to varying physical and biological conditions. The effort will require extensive sampling of the waters of this and adjacent regions.

\section{Too hot for a homecoming?}

How far should scientists go in deliberately attempting to reverse the disappearance of stocks of fish of potential commercial value? The issue has been raised by a project intended in part to establish whether climate warming was responsible for eliminating from English waters Europe's only freshwater member of the cod family.

The fish in question is the burbot (Lota lota), which is still abundant in other, less temperate, regions of Europe. In a pilot project involving 100 specimens imported from the Czech Republic, Jim Reader, a lecturer in life science at the University of Nottingham, is hoping to discover whether it might be reintroduced.

Some fear that climatic conditions could be inappropriate for the fish, which disappeared from Britain 25 years ago. Alwyne Wheeler, former keeper of fishes at the Natural History Museum in London, says that such a reintroduction would be "morally improper". Wheeler claims that the British burbot was doomed to extinction about 12,000 years ago, when the final
"We need a tremendous amount of information, gathered over a broad area and many years, which is where the fishermen come in," says Peter Wiebe, a biologist at the Woods Hole Oceanographic Institution in Massachusetts. "They're out in places we don't have the resources to get to, and it makes sense to enlist their services." Participating fishermen might either collect data during a normal fishing run or go out on special research trips.

The idea has been welcomed by New England fishermen, who have been hit hard by the collapse of local fish stocks as a result of overfishing. "Fishermen are quite receptive to this opportunity," says Rollie Barnaby, a former fisherman who now works for the Sea Grant College Program at the University of New Hampshire (UNH). "Not only can they learn something and contribute to science, they can also earn a little extra money."

Craig Pendleton of Saco, Maine, is one fisherman who is eager to get involved in the

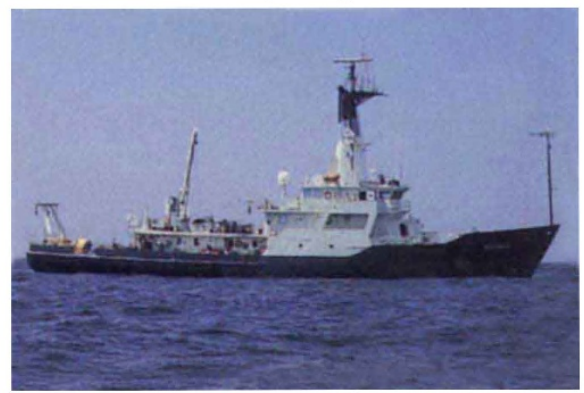

Woods Hole's research vessel Oceanus.

retreat of the ice cap and rising sea levels left it stranded in Britain.

Several freshwater fish, such as the arctic char and races of brown trout, have disappeared from many parts of England since the Industrial Revolution of the eighteenth century. In most cases, this has been blamed on local causes, such as sewage or industrial activity.

In contrast, the burbot, which some say was abundant in lowland rivers in eastern England (and of considerable commercial importance), has disappeared completely, following a few final sightings around 1970.

Unlike most other British freshwater fish, the burbot spawns in mid-winter at temperatures slightly above freezing. Some scientists, such as Wheeler, believe that English mid-winter temperatures are now too warm for the burbot, a result of natural and man-made climate changes that are widely believed to have caused a rise in average global temperatures. Reader accepts that this is a reasonable hypothesis - but one that has yet to be proved either way. project. Owing to government restrictions, Pendleton will only have 88 days this year to fish for cod, haddock and other so-called 'groundfish', leaving him plenty of time for research-related endeavours. He believes that fishing vessels and their crews could offer an economical means of collecting data at sea. "We have a lot of experience in the water and are used to operating as cheaply as possible," he says.

But the goals of the Georges Bank project extend beyond the financial concerns of fishermen and scientific researchers. An equally important objective is to improve relations between the two groups and to enhance understanding on both sides.

"Communications between scientists, government regulators, fishermen and fish processors have never been good," Wiebe says. "Fishermen either don't understand what we're trying to do or they don't believe what we tell them." He hopes this adversarial relationship will turn into a "collaborative process," with scientists learning from fishermen, and fishermen, in turn, becoming better schooled in scientific methods.

\section{Agreement is the starting point}

Ann Bucklin, a biologist at UNH who heads the New Hampshire-Maine Sea Grant College Program, says: "Fishermen need help understanding the biological reasons for the regulations they consider themselves to be 'inflicted' with. The way to fix that problem is to get fishermen involved in the collection of the data that provide the basis for fishery management strategies and regulations."

Scientists frequently rely on fishermen to install or recover monitoring equipment, but the Georges Bank project represents "the first concerted effort in this country to involve fishermen in a major oceanographic research program," according to Bucklin.

Although 70 scientists are participating in the project, the budget to involve fishermen is small — limited, so far, to a single year of funding (1997) and a total of just $\$ 30,000$. The money will barely cover the three research forays planned for fishermen this spring, summer and autumn.

But a proposal will be submitted to expand the budget for 1998. "There may be creative ways of funding this activity, if it turns out to be a good way to go," says Wiebe. Apart from direct grants from the federal government, other possibilities might include tax credits, contributions from the fish-processing industry, and extra fishing days granted to those taking part in the research.

Wiebe sees large potential for cooperative ventures of this nature. "Three years from now, GLOBEC Georges Bank will be completed, but the need for this kind of information will still be here," he says.

SteveNadis 